health behaviour monitoring survey among the Finnish adult population, 1990-1. Material from the general household survey, 1990-1, is Crown copyright; it has been made available by the Office for National Statistics through the data archive and has been used with permission. Data from the Enquête sur la Santé et les Soins Medicaux were provided by Mr and Mrs Mizrahi (Centre de Recherche, d'Etude et de Documentation en Economie de la Santé, France). None of these institutions bear any responsibility for the analysis or interpretation of the data reported here. This study is part of a larger project on socioeconomic inequalities in morbidity and mortality, which is conducted within the framework of a concerted action sponsored by the European Union. The design of the project, the data specifications, and the interpretation of preliminary results were discussed at three workshops.

Contributors: AEJMC organised data collection, carried out the analysis, and wrote a first version of this paper. AEK supervised data collection and analysis and helped in interpreting the data and writing the paper. JPM designed the study, helped in interpreting the data, and wrote the final version of this paper. He will act as guarantor for the paper. The other coauthors collected the data for their own country, helped in interpreting these data, and commented on the paper.

Funding: This study was supported by a grant from the

European Union's Biomed-1 program (CT92-1068).

Conflict of interest: None declared.

1 Vågerö D, Lundberg O. Health inequalities in Britain and Sweden. Lancet 1989;ii:35-6.

2 Van Doorslaer E, Wagstaff A, Bleichrodt H, Burg vdH, Calonge S, Gerdtham U, et al. Income-related inequalities in health: some international comparisons. J Health Econ 1997;16:93-112.

3 Mackenbach JP, Kunst AE, Cavelaars AEJM, Groenhof F, Geurts JIM, EU-Working Group on Socioeconomic Inequalities in Health. Socioeconomic inequalities in morbidity and mortality in Western Europe: a comparative study. Lancet 1997;349:1655-9.

4 Kunst AE, Groenhof F, Mackenbach JP and the EU Working Group on Socioeconomic Inequalities in Health. Occupational class and causespecific mortality in middle aged men in 11 European countries: a comparison of population based studies. BMJ 1998;316:1636-41.

5 Pierce JP. International comparisons of trends in cigarette smoking prevalence. Am J Public Health 1989;79:152-7.

6 Pierce JP. Progress and problems in international public health efforts to reduce tobacco usage. Annu Rev Publ Health 1991;12:383-400.

7 Helmert U, Mielck A, Classen E. Social inequities in cardiovascular disease risk factors in East and West Germany. Soc Sci Med 1992;35; $1283-92$
8 Organization for Economic Co-operation and Development. Education in OECD countries 1987-89. A compendium of statistical information. Paris: OECD, 1990

9 Pamuk ER. Social class and inequality in mortality from 1921 to 1972 in England and Wales. Popul Stud 1985;39:17-31.

10 Kunst AE, Mackenbach JP. Measuring socio-economic inequalities in health Copenhagen: World Health Organisation, 1994.

11 Mackenbach JP, Kunst AE. Measuring the magnitude of socio-economic inequalities in health: an overview of available measures illustrated with two examples from Europe. Soc Sci Med 1997;44:757-71.

12 Patrick DL, Cheadle A, Thompson DC, Diehr P, Koepsell T, Kinne S. The validity of self-reported smoking: a review and meta-analysis. Am J Public Health 1994:84:1086-93.

13 Todd GF. Cigarette consumption per adult of each sex in various countries. J Epidemiol Community Health 1978;32:289-93.

14 Boström G, Hallqvist J, Haglund BJA, Romelsjö A, Svanström L, Diderichsen F. Socioeconomic differences in smoking in an urban Swedish population. The bias introduced by non-participation in a mailed questionnaire. Scand J Soc Med 1993;21:77-82.

15 Suadicani P, Hein HO, Gyntelberg F. Serum validated tobacco use and social inequalities in risk of ischaemic heart disease. Int J Epidemiol 1994;23:293-300

16 Wagenknecht LE, Burke GL, Perkins LL, Haley NJ, Friedman GD. Misclassification of smoking status in the CARDIA study: A comparison of self-report with serum cotinine levels. Am J Public Health 1992;82:33-6.

17 Wewers ME, Dhatt RK, Moeschberger ML, Gurthrie RM, Kuun P, Chen MS. Misclassification of smoking status among Southeast Asian adult immigrants. Am J Respir Crit Care Med 1995;152:1917-21.

18 Kunst AE, Cavelaars AEJM, Groenhof F, Geurts JJM, Mackenbach JP, EU-Working Group on Socioeconomic Inequalities in Health. Socioeconomic inequalities in morbidity and mortality in Europe: a comparative study. Rotterdam: Erasmus University, 1996.

19 Ferraroni M, La Vecchia C, Pagano R, Negri E, Decarli A. Smoking in Italy, 1986-1987. Tumori 1989;75:521-6.

20 La Vecchia C, Gutzwiller F, Wietlisbach V. Sociocultural influences on smoking habits in Switzerland. Int J Epidemiol 1987;16:624-6.

21 Berrino F, Merletti F, Zubiri A, Del Moral A, Raymond L, Esteve J, et al. A comparative study of smoking, drinking and dietary habits in population samples in France, Italy, Spain and Switzerland. II Tobacco smoking. Rev Epidém et Santé Publ 1988:36:166-76.

22 Sasco AJ, Grizeau D, Pobel C, Chatard O, Danzon M. Tabagisme et classe sociale en France de 1974 à 1991. Bulletin Cancer 1994;81:355-9.

23 Cavelaars AEJM, Kunst AE, Mackenbach JP. Socio-economic difference in risk factors for morbidity and mortality in the European Community: an international comparison. J Health Psychol 1997;2:353-72.

24 Peto R, Lopez AD, Boreham J, Thun M, Heath C. Mortality from smoking in developed countries 1950-2000: indirect estimates from national vital statistics. Oxford: Oxford University Press, 1994.

25 Graham H. Smoking prevalence among women in the European community 1950-1990. Soc Sci Med 1996;43:243-54.

(Accepted 2 January 2000)

\title{
Evaluating "payback" on biomedical research from papers cited in clinical guidelines: applied bibliometric study
}

\author{
Jonathan Grant, Robert Cottrell, Françoise Cluzeau, Gail Fawcett
}

\begin{abstract}
Objectives To develop a methodology for evaluating the impact of research on health care, and to characterise the papers cited on clinical guidelines. Design The bibliographic details of the papers cited in 15 clinical guidelines, developed in and for the United Kingdom, were collated and analysed with applied bibliometric techniques.

Results The median age of papers cited in clinical guidelines was eight years; most papers were published by authors living in either the United States $(36 \%)$ or the United Kingdom (25\%) - this is two and a half times more than expected as about $10 \%$ of all biomedical outputs are published in the United Kingdom; and clinical guidelines do not cite basic research papers.

Conclusion Analysis of the evidence base of clinical guidelines may be one way of tracking the flow of knowledge from the laboratory to the clinic.
\end{abstract}

Moreover, such analysis provides a useful, clinically relevant method for evaluating research outcomes and different strategies in research and development.

\section{Introduction}

The United Kingdom spends over $£ 1600$ million a year on non-commercial biomedical and health services research. ${ }^{1}$ This research is funded either from the public purse, such as the NHS and the Medical Research Council, or medical research charities, such as the Wellcome Trust. The tacit understanding is that the biomedical research these bodies support will lead to an eventual improvement in health. The system is highly complex, however, and medical agencies support a wide spectrum of activity from basic biomedical research through to research in health services and assessments of technology. Notwithstanding this complexity, there is a need to understand how
Policy Unit, Wellcome Trust, London NW1 2BE

Jonathan Grant policy advisor

Robert Cottrell policy officer

Gail Fawcett policy officer

Health Care Evaluation Unit, St George's Hospital Medical School, London SW17 0RE

Françoise Cluzeau lecturer in health services

Correspondence to: J Grant j.grant@wellcome. ac.uk

BMJ 2000;320:1107-11 


\begin{tabular}{llr}
\hline Table 1 & Code, title, and reference of 15 "appraised" guidelines & Reference \\
Code & Guideline title & 4 \\
\hline ACE & ACE inhibitors in the primary care management of adults with symptomatic heart failure & 5 \\
\hline ANG & The primary care management of stable angina & 6 \\
\hline ASP & Aspirin for the secondary prophylaxis of vascular disease in primary care & 7 \\
\hline BAC & Clinical guidelines for the management of acute low back pain & 8 \\
\hline DEM & The primary care management of dementia & 9 \\
\hline DEP & The choice of antidepressants for depression in primary care & 10 \\
\hline EPI & Adults with poorly controlled epilepsy & 11 \\
\hline GLI & Improving care for patients with malignant cerebral glioma & 12 \\
\hline INF & The management of infertility in secondary care & 13 \\
\hline MEN & The initial management of menorrhagia & 14 \\
\hline NSA & Non-steroidal anti-inflammatory drugs (NSAIDs) versus basic analgesia in the treatment & 15 \\
\hline OST & of pain believed to be due to degenerative arthritis & 16 \\
\hline SPE & Clinical guidelines for strategies to prevent and treat osteoporosis & 17 \\
\hline VIO & Clinical guidelines by consensus for speech and language therapists & 18 \\
\hline WHE & The management of imminent violence & The primary care management of asthma in adults \\
\hline
\end{tabular}

funding of research affects health care. Such analysis will allow funding agencies to show accountability and good research governance to their stakeholders; enhance public perception and understanding of biomedical science and the scientific process; and allow the development of more effective strategies in research and development to increase the likelihood of "successful" research outcomes. ${ }^{2}$

Traditionally, the contribution of scientific research to knowledge has been measured by the number and impact of scientific papers in the peer reviewed literature. A broader approach has suggested disaggregating the research process and assessing the "payback" at each stage. ${ }^{3}$ A pilot study has shown that it is possible to use applied bibliometric techniques to "link" research funding organisations with both primary and secondary outputs. ${ }^{2}$ Primary outputs are defined as publications in the serial peer reviewed literature, while the secondary outputs are taken to be evidence based clinical guidelines. We expanded on the pilot study by increasing the sample size to permit us to characterise the papers cited on clinical guidelines.

\section{Data sources}

Fifteen sets of guidelines on disease management were selected as data sources for the study (table 1). ${ }^{4-18}$ The guidelines covered a range of conditions seen in general (family) practice or in hospital care, and all had been produced in the United Kingdom, either by the royal colleges or by the North of England Evidence Based Guidelines Development Project. The guidelines were selected because they had been assessed by the NHS Appraisal Centre for Clinical Guidelines. The role of the centre is to advise the NHS Executive about the quality of clinical guidelines that have been funded through the national guideline programme. ${ }^{19}$ Its appraisal consists of a structured peer review based on a validated appraisal instrument that assesses key elements for the development and reporting of clinical guidelines. ${ }^{20}$

\section{Methods}

One criterion on which the guidelines are appraised is the "identification and interpretation of evidence." Accordingly, a well developed guideline would include a comprehensive bibliography of publications cited therein. We scanned these bibliographic details onto a bespoke database. After we standardised the bibliographic data we looked up all papers on the Science Citation Index and in libraries to add the addresses of the authors and any missing information such as paper titles, volume numbers, etc.

When possible, we made comparisons with all UK biomedical publications between 1988 and 1995 using the Wellcome Trust's research output database (ROD). ${ }^{1}$ Analyses were based on either paper or journal details and included examination of the "knowledge cycle time" (the time between a paper's publication and its citation in a clinical guideline); the country of authorship, based on analysis of the address fields; and the type of research cited (the extent to which basic (or clinical) research was cited in guidelines).

This last analysis used a journal classification system developed and updated by CHI Research (a private research consultancy based in the United States). The system is based on expert opinion and journal to journal citations and has become a standard tool in bibliometric analyses. ${ }^{21}$ Journals are allocated to four hierarchical levels in which each level is more likely to cite papers in journals at the same level or the level below it. Hence, only $4 \%$ of papers in level 1 "clinical observation" journals (for example, BM/) will cite papers in level 4 "basic" journals (for example, Nature) compared with $8 \%$ for level 2 "clinical mix" journals (for example, New England Journal of Medicine) and 21\% for level 3 "clinical investigation" journals (for example, Immunology). By looking at the journals in which papers cited in clinical guidelines are published, it is possible to characterise the research and estimate how long it takes for basic research to feed into clinical practice. This analysis, however, is rather crude as it allocates all papers within a journal to one level, despite a strong likelihood that there is variation in the type of research published in a given journal.

\section{Results}

Table 2 shows the characteristics of the papers cited in the 15 guidelines. In total, 2501 papers were referenced in the bibliographies of the guidelines, of which 2043 (82\%; range 50-98\%) were papers in research journals. A small proportion of papers (55; $3 \%$ ) were referenced in more than one guideline but were still included in the following analyses and therefore were "double counted." Of the 2043 papers looked up in libraries, 1761 (88\%; range 63-100\%) were found and missing information (for example, addresses) recorded.

\section{The "knowledge cycle time"}

In patent analysis, an important characteristic is the "prior art cycle time," which is defined as the median age of the patents referenced on the front page of a patent. ${ }^{22}$ With guidelines, an analogous indicator would be the "knowledge cycle time"-that is, the age of papers cited in clinical guidelines, as illustrated in figure 1 . The median knowledge cycle time for all 15 guidelines was eight years; $25 \%$ of the papers, however, were more than 10 years old and $4 \%$ more than 25 years old. 
Table 2 Number of references, papers, and found papers, by guideline

\begin{tabular}{lccc} 
Code & $\begin{array}{c}\text { No of } \\
\text { references }\end{array}$ & $\begin{array}{c}\text { No }(\%) \text { of } \\
\text { papers }{ }^{*}\end{array}$ & $\begin{array}{c}\text { No (\%) of } \\
\text { found papersł }\end{array}$ \\
\hline ACE & 86 & $60(70)$ & $54(90)$ \\
\hline ANG & 123 & $116(94)$ & $107(92)$ \\
\hline ASP & 132 & $130(98)$ & $93(72)$ \\
\hline BAC & 68 & $53(78)$ & $46(87)$ \\
\hline DEM & 153 & $143(93)$ & $119(83)$ \\
\hline DEP & 258 & $236(91)$ & $183(78)$ \\
\hline EPI & 107 & $85(79)$ & $67(79)$ \\
\hline GLI & 112 & $82(73)$ & $71(87)$ \\
\hline INF & 588 & $466(79)$ & $434(93)$ \\
\hline MEN & 127 & $100(79)$ & $85(85)$ \\
\hline NSA & 48 & $33(69)$ & $33(100)$ \\
\hline OST & 422 & $337(80)$ & $314(93)$ \\
\hline SPE & 122 & $61(50)$ & $47(77)$ \\
\hline VI0 & 89 & $87(98)$ & $55(63)$ \\
\hline WHE & 66 & $54(82)$ & $53(98)$ \\
\hline Total & 2501 & $2043 \S(82)$ & $17619(84)$ \\
\hline
\end{tabular}

*Papers are defined as scientific publications in peer reviewed literature-that is, not reports, book chapters, etc.

†Denominator is number of references.

†Denominator is number of papers.

§Includes 55 papers cited in more than one guideline.

IIncludes 54 papers cited in more than one guideline.

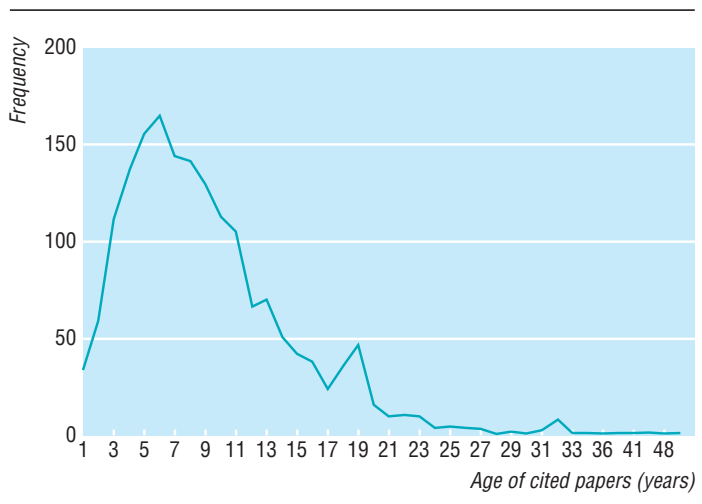

Fig 1 Age of papers cited in clinical guidelines

\section{Country of authorship}

Figure 2 shows the distribution of the addresses of authors cited in the clinical guidelines for the Group of Seven (G7) largest economies. Comparison data for outputs in 1998 were taken from the Science Citation Index with a title keyword and specialist journal search strategy developed for biomedicine and described elsewhere. ${ }^{1}$ In total 9007 authors were cited in the 1761 papers, which is an average of 5.1 authors per paper. This distribution is heavily skewed as five papers had more than 100 authors. Most papers were published by authors living in either the United States $(36 \%)$ or the United Kingdom (25\%), with the five remaining countries accounting for $19 \%$ of addresses. Non-G7 countries accounted for $26 \%$ of the papers. Note that for a number of the guidelines the total percentages add up to more than $100 \%$ because of collaboration between the G7 countries. The most salient observation to be made from figure 2 is the higher proportion of UK papers cited in guidelines compared with biomedicine as a whole.

Type of cited research

The third analysis was based on the journals in which the cited papers appeared and was used to determine

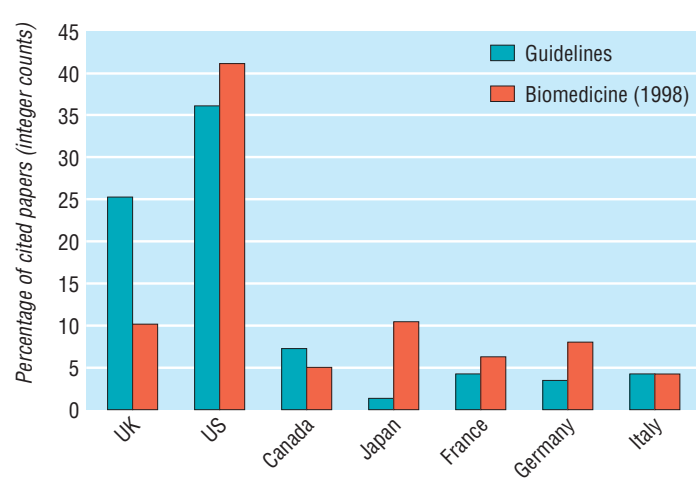

Fig 2 Nationality of authors of papers cited in clinical guidelines

the extent to which basic or clinical research is cited in clinical guidelines. Figure 3 shows the distribution of cited papers across four different journal levels. Of the 1761 papers, $260(15 \%)$ did not have a research level. Of the remaining papers, nearly three quarters appeared in level 1 (clinical observation) or level 2 (clinical mix) research journals compared with only four papers (or $0.2 \%$ ) in level 4 (basic) journals.

Comparison data were taken from the research output database for UK biomedical publications between 1988 and 1995 (the right hand column for each research level in figure 3). To make this comparison valid, however, the guideline papers have been restricted to the 291 UK publications between 1988 and 1995 (the middle column for each research level). As is apparent from figure 3 clinical guidelines are citing clinical papers. In itself this observation is not surprising, though there is an underlying assumption in biomedical science policy that basic research feeds into clinical practice. To see if this assumption holds, figure 4 examines the type of research cited in subsequent "generations" of papers, where a second generation paper refers to papers cited in a $5 \%$ random sample of papers cited in the guideline papers and a third generation paper to a $5 \%$ random sample of papers cited in a 5\% random sample of papers cited in the guideline papers and so on. In this analysis the proportion of clinical observation (level 1) papers fell from $30 \%$ to $14 \%$ over the four generations analysed while basic (level 4) papers increased from $0.2 \%$ to $8 \%$.

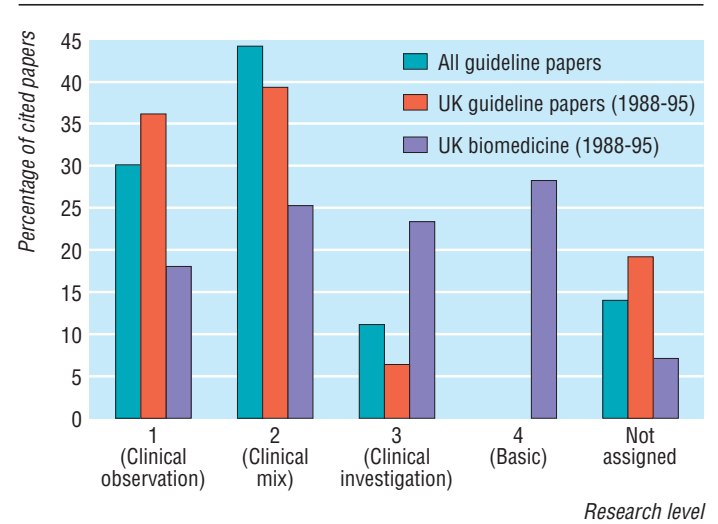

Fig 3 Research level of journals cited in clinical guidelines 


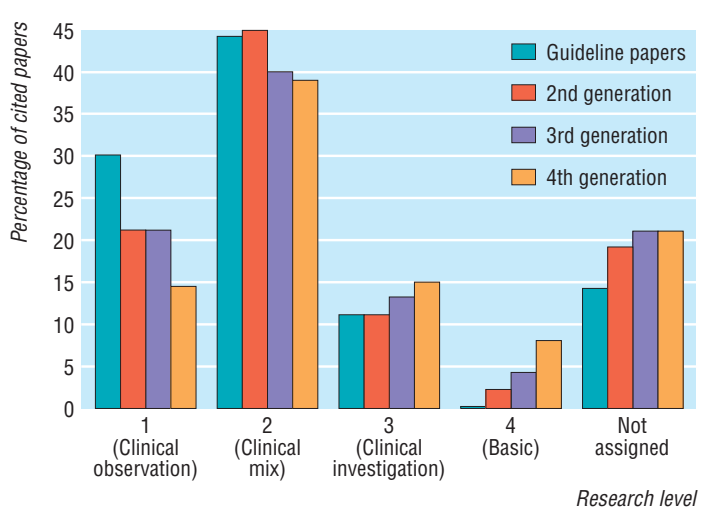

Fig 4 Research level of journals cited in subsequent generations of papers

\section{Discussion}

\section{Policy implications}

This study raises a number of important policy issues. Potentially the most important observation is in figure 2, which shows that authors of UK guidelines are citing UK papers. This may suggest that the guidelines are not citing all the internationally available evidence and that there is a publication bias. This explanation is unlikely, however, because the appraisal criteria specifically assess whether the identification, evaluation, and selection of evidence have been properly conducted and are unbiased. That said, it would be interesting to see if US guidelines cite US papers or whether in the United Kingdom a disproportionate volume of papers relevant to guidelines is published. Furthermore, guidelines informed by local (UK) research might not be a bad thing per se. Indeed, the preferential citing of UK papers may provide good evidence for supporting a local science base. If so, then the central policy question is: does a strong science base lead to better clinical practice? As far as we are aware, this assumption has never been fully tested. One way would be to link data on research evaluation (such as the number and quality of peer reviewed publications) with data on clinical audit (such as standardised mortality adjusted for case mix).

A second observation is the length of time it takes for basic research to flow into clinical practice. It has been shown that on average it takes three years for a paper to be cited, ${ }^{23}$ and figure 1 shows an average eight year time lag between the publication of a paper and the publication of a guideline. In other words, it would seem to take about 17 years (that is, $8+(3 \times 3)$ ) for the fourth generation research papers to feed into clinical practice. From a policy viewpoint, this raises the question of what the optimum time is for research to be fully evaluated and put into practice and whether this process needs to and can be speeded up.

A related issue is how basic research supports clinical research. Figure 4 shows that basic research is not being cited in clinical guidelines, and although the proportion increases by generation, only $8 \%$ of basic research is cited at the fourth generation of papers. It is hard to estimate how much basic research one would expect to be cited at the fourth generation, but it is significantly below the $25 \%$ for all UK biomedicine. Does this imply that there is little interaction between the clinical and basic research communities? Or is the information flowing through other routes, such as tacit knowledge, medical education, etc? Interestingly, these findings are at odds with those of past studies, which have concluded that basic research is an essential bedrock of clinical medicine. ${ }^{24}$ These studies and the current analysis, however, take a retrospective lookthat is, they identify a success (such as a citation in a clinical guideline or a medical advance) and look at the supporting evidence. An alternative approach would be to identify a body of basic research published some time ago and follow its subsequent knowledge flow. This would further our understanding of how research feeds into medical (or non-medical) advances.

\section{Methodological limitations}

This study has shown how applied bibliometric techniques can be used to generate and inform several interesting policy issues in research and development and provide a way to evaluate the impact of research on clinical practice. There are, however, several limitations to our approach. Firstly, our analysis is based on "found papers." These account for $70 \%$ of all references cited in clinical guidelines, and thus there could obviously be biases in our results if the papers we failed to find had significantly different characteristics to those analysed. Secondly, a citation in a clinical guideline does not guarantee an impact on health and therefore a payback on the research investment. Nevertheless, a citation in a clinical guideline could be considered as an indicator of research utility and thus an intermediate outcome, or "secondary output" in the language of the payback model. Thirdly, bibliometric analysis does not give any indication of the importance of a cited paper. This problem could be overcome by assigning weights to papers on the basis of quality, sample size, or such like. Finally, the analysis was undertaken in the absence of a denominator. Only the "successful" papers were examined, and we do not know how many papers have been published that are potentially relevant to the topics covered by the guidelines but were not cited in the clinical guideline.

\section{Towards an evidence based research policy}

Despite these limitations, we would strongly defend this type of analysis and encourage other investigators to spend some time thinking about the way research is managed. In one sense the lack of solid conclusions reflects the lack of evidence in this area. This is despite recognition in the $B M J$ in 1987 that "we need to research research" ${ }^{\prime 25}$ and the strong methodological synergy between epidemiology, especially in the analysis of observational datasets, and evaluation of quantitative research as presented in this paper. Indeed, in a period when researchers are demanding that clinicians practice evidence based medicine it is only appropriate and correct that such researchers audit and evaluate the research outputs and outcomes of their own investigations.

Contributors: JG conceived, initiated, and coordinated the project and participated in the analysis and writing of the paper. RC developed and managed the data collection procedure and participated in the analysis of the data. FC collated and supplied the clinical guidelines and provided expert advice on guidelines, 


\section{What is already known on this topic}

Research evaluations have traditionally assessed contributions to knowledge through citation analysis

The objective of many agencies that fund medical research is to support research that improves health, and therefore conventional bibliometric analysis, which assesses contributions to knowledge, may not be an appropriate method of evaluation

\section{What this study adds}

The use of clinical guidelines as an intermediate outcome measure in the research process is a novel method of applying bibliometric techniques to assess the impact of research on health care

their quality and formulation. GF participated in the analysis and presentation of the data. JG is guarantor.

Funding: JG, RC, and GF work at, and are therefore intramurally supported by, the Wellcome Trust. FC works at the Health Care Evaluation Unit, which is supported by the research and development offices of the South East and London NHS regional offices.

Competing interests: None declared.

1 Dawson G, Lucocq B, Cottrell R, Lewison G. Mapping the landscape National biomedical outputs 1988-95. London: Wellcome Trust, 1998.

2 Grant J. Evaluating the outcomes of biomedical research on healthcare. Res Eval 1999;8:33-8.

3 Buxton M, Hanney S. How can payback from health services research be assessed? J Health Services Res Policy 1996;1:35-43.

4 North of England Evidence Based Guideline Development Project. ACE inhibitors in the primary care management of adults with symptomatic heart failure. Newcastle upon Tyne: Centre for Health Services Research, University of Newcastle upon Tyne, 1998.

5 North of England Evidence Based Guideline Development Project. The primary care management of stable angina. Newcastle upon Tyne: Centre for Health Services Research, University of Newcastle upon Tyne, 1996.
6 North of England Evidence Based Guideline Development Project. Aspirin for the secondary prophylaxis of vascular disease in primary care. Newcastle upon Tyne: Centre for Health Services Research, University of Newcastle upon Tyne, 1998

7 Waddell G, Feder G, McIntosh A, Lewis M, Hutchinson A. Low back pain evidence review. London: Royal College of General Practitioners, 1996.

8 North of England Evidence Based Guideline Development Project. The primary care management of dementia. Newcastle upon Tyne: Centre for Health Services Research, University of Newcastle upon Tyne, 1998.

9 North of England Evidence Based Guideline Development Project. The choice of antidepressants for depression in primary care. Newcastle upon Tyne: Centre for Health Services Research, University of Newcastle upon Tyne, 1998.

10 Wallace H, Shorvon SD, Hopkins A, O'Donoghue M. Adults with poorly controlled epilepsy. London: Royal College of Physicians, 1997.

11 Davies E, Hopkins A. Improving care for patients with malignant cerebral glioma. London: Royal College of Physicians, 1997.

12 Royal College of Obstetricians and Gynaecologists. The management of infertility in secondary care. London: RCOG, 1998

13 Royal College of Obstetricians and Gynaecologists. The initial management of menorrhagia. London: RCOG, 1998.

14 North of England Evidence Based Guideline Development Project. Nonsteroidal anti-inflammatory drugs (NSAIDs) versus basic analgesia in the treatment of pain believed to be due to degenerative arthritis. Newcastle upon Tyne: Centre for Health Services Research, University of Newcastle upon Tyne, 1998.

15 Royal College of Physicians. Clinical guidelines for strategies to prevent and treat osteoporosis. London: Royal College of Physicians, 1998.

16 Enderby P, Reid D, Van der Gaag A. Clinical guidelines by consensus for speech and language therapists. Glasgow: M and M Press, 1998.

17 Royal College of Psychiatrists. The management of imminent violence. London: Royal College of Psychiatrists, 1998.

18 North of England Evidence Based Guideline Development Project. The primary care management of asthma in adults. Newcastle upon Tyne: Centre for Health Services Research, University of Newcastle upon Tyne, 1996.

19 Cluzeau F, Littlejohns P. Appraising clinical practice guidelines in England and Wales: the development of a methodologic framework and its application to policy. Joint Commission J Qual Improve 1999;25:514-21.

20 Cluzeau F, Littlejohns P, Grimshaw J, Feder G, Moran S. Developmen and application of a generic methodology to assess the quality of clinical guidelines. Int J Oual Health Care 1999;11:23-8.

21 Narin F, Pinski G, Gee H. Structure of the biomedical literature. J Am Soc Inform Sci 1976;27:25-45.

22 Anderson J, Williams N, Seemungal D, Narin F, Olivastro D. Human genetic technology: exploring the links between science and innovation. Technol Anal Strategic Manage 1996;8:135-56.

23 Grant J, Lewison G. Government funding of research and development. Science 1997:278:878-80.

24 Comroe J, Dripps R. Scientific basis for the support of biomedical science. Science 1976;192:105-11.

25 Smith R. Comroe and Dripps revisited. BMJ 1987;295:1404-7.

(Accepted 20 January 2000)

\section{A golden rule Looking first}

"It's a game, and you have to know the rules," they said about the membership examination. Tricks of the trade were explained in great detail by ranks of registrars and senior house officers on the other side of this impossibly high fence I had to jump. One consultant, however, simply advised me to "just stop and look before you dive in."

She was clearly very elderly, sitting there in the chair-that is all I remember thinking on the approach.

"Examine this lady's fundi please."

I leapt in, introduced myself, and put out my hand-got to look confident, got to look like the registrar. Bilateral optic atrophy. I had never seen it more obviously. Now, causes, causes, got to have the causes. I turned to face the examiner and looked him in the eye.

"This lady has bilateral optic atrophy." I was on a roll now; picking up the signs - this was "the game" and I had all the aces at the moment.

"What is her acuity?" the examiner asked. The "roll" came to an abrupt halt. There was no Snellen chart to hand, what could he mean? He hadn't asked for that in the original instruction. Where was the catch? I struggled and blurted out the first thing I could think of.

"Well, she fumbled slightly for my hand when I went to shake hers, so I suppose the acuity is reduced, but I would need to test it formally of course." It sounded lame. He just stared at me.
"Are there any other clues that this lady has poor acuity, doctor?"

Now he had the look, the "smiling death" I had been told about. What had I missed? I turned back to face the patient and allowed myself for the first time to "just stop and look."

From under her chair, and only visible when I stood back from the patient, her guide dog seemed to be grinning at me.

I didn't fail simply because of that-there were other more fundamental errors to come-but it was a simple lesson that I have tried to apply since- to "just stop and look before diving in." Martin Turner MRCP research registrar in neurology, London

We welcome articles of up to 600 words on topics such as A memorable patient, A paper that changed my practice, My most unfortunate mistake, or any other piece conveying instruction, pathos, or humour. If possible the article should be supplied on a disk. Permission is needed from the patient or a relative if an identifiable patient is referred to. We also welcome contributions for "Endpieces," consisting of quotations of up to 80 words (but most are considerably shorter) from any source, ancient or modern, which have appealed to the reader. 